\title{
Treatment of the Rust Layer by Different Pyridine Derivatives and Its Effect on the Epoxy-Polyvinylbutyral Coating Directly Painted onto the Rust Mild Steel
}

\author{
Yinze Zuo, Zhaolei Li ${ }^{*}$, Liang Chen, Yu Wang, Yanmin Gao \\ School of Materials Science and Engineering, National Demonstration Center for Experimental \\ Materials Science and Engineering Education, Jiangsu University of Science and Technology, \\ Zhenjiang 212003 \\ *E-mail: zllinju@126.com
}

doi: $10.20964 / 2017.12 .42$

Received: 21 July 2017 / Accepted: 9 October 2017 / Published: 12 November 2017

In this work, 2-picolinicacid, 2-hydroxypyridine and 2-aminopyridine were used as rust converters to pre-process a metal surface. The results showed that the rust layers of A3 steel treated by pyridine derivatives are more compact and homogeneous than the untreated rust layer. The corrosion rate of the mild steel treated by 2-hydroxypyridine is lower, and the impedance is the highest compared to those of the rust layers treated by 2-picolinicacid and 2-aminopyridine as well as the untreated one. The epoxy-polyvinylbutyral (EP-PVB) coating was directly painted onto an untreated rust layer and those treated by pyridine derivatives. The adhesion of EP-PVB coatings directly painted onto the treated rust layers is much higher than that directly painted onto the untreated surface. The coatings also provide corrosion resistance, demonstrating good performance after the coatings were immersed in $3.5 \% \mathrm{NaCl}$ solution for 2 days or 30 days.

Keywords: corrosion, rust layer, pyridine derivatives, electrochemical properties, adhesion

\section{$\underline{\text { FULL TEXT }}$}

(C) 2017 The Authors. Published by ESG (www.electrochemsci.org). This article is an open access article distributed under the terms and conditions of the Creative Commons Attribution license (http://creativecommons.org/licenses/by/4.0/). 